Fiscaoeconomia

E-ISSN: 2564-7504

2021, Volume 5, Issue 2, 404-417

https://dergipark.org.tr/tr/pub/fsecon
Research Article/Araştırma Makalesi

Submitted/Geliş: 04.03.2021

Accepted/Kabul: 20.03.2021

Doi: 10.25295/fsecon.891169

\title{
Eski ve Yeni Kurumsal Ekole Heterodoks Bir Bakış
}

A Heterodox View to the Old and New Institutional School

\section{Ecem TURGUT ${ }^{1}$, Yeliz Sarıöz GÖKTEN ${ }^{2}$, Okyay UÇAN ${ }^{3}$}

\begin{abstract}
Öz
İktisadi düşünce tarihi içerisinde birçok ekol varlık göstermiş ve metodolojik olarak birbirlerinden farklı özellikler sergilemişlerdir. Bazı ekoller, fen bilimlerinde olduğu gibi yer ve zaman koşulu gözetmeden her şartta geçerli olacak genel geçer kanunların ve kuralların ekonominin bilimin temeli olacağını ileri sürmüşler ve matematiği de analizlerinin temeline yerleştirerek amaç haline getirmişlerdir. Bu ekoller ortodoks iktisat akımı bünyesinde değerlendirilmişlerdir. Bazı ekoller ise, ekonominin sosyal bir bilim olduğunu, karşılaşılan sorunların toplumsal karakter taşıdığını dolayısıyla toplumdan bağımsız düşünülemeyeceğini savunmuştur. Buradan hareketle her şartta ve her zaman diliminde geçerli olacak bir genel geçer kuralların kabul edilemeyeceğini ve matematiğin ekonomi biliminde bir amaç olmaktan ziyade bir araç olarak değerlendirilebileceğini savunmuşlardır. Bu düşünce yapısına sahip ekoller ise heterodoks iktisat akımları olarak değerlendirilmiştir. Heterodoks teori denildiğinde akla ilk gelen ekollerden biri kurumsal iktisattır. Çalışmada kurumsal iktisadın heterodoks mu yoksa ortodoks iktisat akımı içerisinde mi değerlendirilmesi gerektiğine yönelik tartışmalar yürütülecektir. Kurumsal iktisat, iktisadi düşüncenin gelişiminde önemli bir rol oynamaktadır. Kurumsal iktisat, neoklasik iktisadın rasyonel insan, denge, tümdengelim ve soyutlamalara dayalı analizine alternatif olarak iktisadi sistemde kurumların önemine vurgu yapmıştır. Çalışmada Yeni Kurumsalcıların heterodoks iktisat bünyesinde değerlendirilmesi düşüncesine şüphe ile yaklaşılırken, genel olarak Eski Kurumsal iktisadın neoklasik iktisat öğretisine karşı çıkmalarının etkisiyle heterodoks iktisat akımı kapsamında olduğu değerlendirilmiştir.
\end{abstract}

Jel Kodları: $B 15, B 25, B 52, P 26, P 48$

Anahtar Kelimeler: Kurumsal iktisat, Ana akım Iktisat, Ortodoks, Heterodoks

\footnotetext{
${ }^{1}$ Doktora Öğrencisi, Niğde Ömer Halisdemir Üniversitesi, íktisat Bölümü, ecemtrgtt@gmail.com, ORCID:00000003-2385-1580

${ }^{2}$ Doç. Dr., Niğde Ömer Halisdemir Üniversitesi, îktisat Bölümü, yezsarioz@hotmail.com, ORCID:0000-0002-69009017

${ }^{3}$ Prof. Dr., Niğde Ömer Halisdemir Üniversitesi, iktisat bölümü, okyayu@hotmail.com, ORCID:0000-0001-52214682
}

Citation/Atıf: Turgut, E., Sarı̈z Gökten, Y. \& Uçan, O. (2021). Eski ve yeni kurumsal ekole heterodoks bir bakış. Fiscaoeconomia, 5(2), 404-417. doi: 10.25295/fsecon.891169 
Turgut, E., Sarıöz Gökten, Y. \& Uçan, O. (2021). Eski ve yeni kurumsal ekole heterodoks bir bakış.

Fiscaoeconomia, 5(2), 404-417. doi: 10.25295/fsecon.891169

\begin{abstract}
In the history of economic thought, many schools have existed, and these schools exhibited different characteristics from each other as methodological. Some schools have argued that economics will be the basis of science, and that there are the general laws and rules that will be valid in all conditions regardless of place and time like in physical science, and these schools have placed mathematics as the basis of their analysis and made a goal. These schools have been evaluated within the orthodox economic approach. Some schools argued economics is a social science, and the problems encountered have a social characteristic, so it cannot be considered independent from society. From this point of view, they argued that no general rules that would be valid in every condition, and time. They also argued that mathematics can be considered as a tool rather than a goal in economics. Schools that have this mentality are considered as heterodox economic approaches. Institutional economics is one of the schools that first come to mind, when it is called heterodox theory. In the study, discussions will be made about whether institutional economics should be evaluated within a heterodox or an orthodox economic trend. Institutional economics plays an important role in the development of economic thought. Institutional economics emphasize the importance of institutions in the economic system as an alternative to the analysis of Neoclassical economics based on rational human, equilibrium, deductive and abstraction. In the study, while the idea of evaluating the New institutionalists within heterodox economics is approached with suspicion, it is generally evaluated that Old Institutional economics is within the scope of heterodox economics due to their opposition to Neoclassical economics doctrine.
\end{abstract}

Jel Codes: $B 15, B 25, B 52, P 26, P 48$

Keywords: Institutional Economics, Mainstream Economics, Orthodox, Heterodox

\title{
1. Giriş
}

İktisadı genel geçer yasalarla açıklama çabalarının temeli pozitivizme dayanır. On sekizinci yüzyıldan itibaren bilgiye ulaşmanın tek yolu olarak kabul edilen pozitivizmde, bilim ve bilim olmayanı ayırmak adına ölçütler belirlenmeye çalışımıştır. Bu ölçütlere uymayan bilgilerin de bilimsel olmadıkları kabul edilmiştir. Pozitivizme dair farklı görüşler mevcut olmakla birlikte en genel hatlarıyla pozitivizm şu şekilde özetlenebilir (Beed, 1991: 462-463):

a) Bilimsel bilgi tek geçerli bilgidir.

b) Metafizik önermeler, doğa bilimleri dışında kalanlar, değer yargıları ve görüşler geçerli bilgi değildir.

c) Matematik ve mantık haricinde ampirik veriler tek geçerli bilgi kaynağıdır.

d) Fizik ve diğer doğa bilimlerinin yöntemleri ile matematik ve mantık aracılığıyla geçerli bilgi elde edilebilir.

e) Bilimde genellemeler, ilkeler ve teoriler, sadece ampirik verilerden türetilebilir.

f) Bilimde genellemeler, ilkeler ve teoriler, ampirik veriler ile doğrulanabilir olmalıdır.

g) Bilimde genellemeler, ilkeler ile teoriler, mantık ve matematik aracılığıyla ifade edilebilmelidir. 
Turgut, E., Sarıöz Gökten, Y. \& Uçan, O. (2021). Eski ve yeni kurumsal ekole heterodoks bir bakış.

Fiscaoeconomia, 5(2), 404-417. doi: 10.25295/fsecon.891169

h) Normatif görüşler, değer yargıları, inançlar ve görüşler ampirik veri toplama sürecine dahil edilemez.

i) Tüm alanlarda geçerli bilgiye ulaşma yöntemi aynı ve tekdir.

Pozitivizmden hareketle iktisat biliminde de doğa bilimlerinde olduğu gibi tüm toplumları ve koşulları kapsayan, zamandan ve mekândan bağımsız genel geçer yasalar oluşturma çabasına girilmiştir. Bunun bir sonucu olarak iktisatta yöntem tartışmaları alevlenmiş, ortodoks ve heterodoks ayrımı türemiştir.

Ortodoks teori denildiğinde ilk akla gelen ekol kuşkusuz neoklasik iktisattır. Bu ekol diğer doğa bilimlerinde olduğu gibi evrensel, genel geçer yasaları olan bir iktisat yaratma gayretine girmiştir. Bunu yapmak için de fizik biliminin kullandığı genel denge iktisada adapte edilmiş, iktisat ve toplum arasındaki ilişki yerini soyutlamalara, matematiğe ve modellemelere bırakmıştır. Bu bağlamda metodolojik bireycilik, genel denge, rasyonel birey, fayda, görünmez el, serbest piyasa gibi kavramlarla iktisadi olaylar açıklanmaya çalışılmıştır. Yine iktisadın pozitif olması önündeki engelleri kaldırmak adına gelenekler, değer yargıları, adetler, din, ahlak, alışkanlıklar, sınıf ilişkileri ve benzeri bütün toplumsal ilişkiler analiz dışı bırakılmıştır ${ }^{4}$.

Ortodoks iktisatçılar analizlerinde toplumu göz ardı eder. Aslında iktisat sosyal bir bilimdir ve adeta toplumun içine gömülenmiştir ${ }^{5}$. Diğer bir deyişle iktisadı toplumdan bağımsız düşünmek mümkün değildir. Bu doğrultuda heterodoks iktisat, ortodoksların ileri sürdüğü gibi genel geçer, her ortamda, toplumda ve zamanda geçerli bir iktisat teorisinin var olamayacağını ifade eder. Heterodoks iktisadın analizine toplumsal ortam, zevk ve tercihler, dini inanışlar, kültür ve gelenekler, sınıfsal ilişkiler dahil edilmiş böylece iktisat ve toplum arasındaki bağın yeniden sağlanmasına çalışı ımıştır. Bu yaklaşımda ana akım iktisadın matematiği iktisat biliminin amacı haline getirmesi ve onu adeta fetişleştirmesi eleştirilmiş; matematiğin ancak analizlerde kullanılabilecek bir araç olabileceği savunulmuştur. Heterodoks iktisadın en bilinen okullarından biri kuşkusuz kurumsal iktisattır.

Kurumsal iktisat, neoklasik ekolün rasyonel bireye, kâr ve fayda maksimizasyonuna, tümdengelime ve soyutlamalara dayalı yöntemine karşı çıkarak ekonomide kurumların önemine vurgu yapmıştır. Bununla birlikte kurumsal iktisat kendi içerisinde dallara ayrılmıştır. Yeni Kurumsalcılar, geleneksel kurumcuların neoklasik iktisada tamamen karşı çıkmasını eleştirmiş, bu doğrultuda bir taraftan neoklasik ekolün gerçek dışı varsayımları reddedilirken diğer taraftan bu anlayışın katı çekirdeği korunmaya çalışılmıştır. Kurumsalcılar içerisindeki bu ayrımın bir sonucu olarak kurumsal iktisadın ortodoks mu yoksa heterodoks mu olduğuna yönelik tartışmalar alevlenmiştir.

Bu çalışmada öncelikle heterodoks akımın ve kurumsal iktisadın temel özellikleri ortaya konulacaktır. Ardından Eski ve Yeni Kurumcu okul arasındaki ayrım gözler önüne serilerek Eski-

\footnotetext{
${ }^{4}$ Polanyi (1996), karşılıklılık, yeniden dağıtım, hanehalkı ve piyasalardan oluşan iktisadi ilişkilerin neoklasik iktisatla birlikte sadece piyasalara indirgendiğini ve diğer unsurların göz ardı edildiğini ifade eder. Bkz. Polanyi (1996), The Great Transformation: The Political and Economic Origins of Our Time, Beacon Press, Boston.

${ }^{5}$ iktisat ve toplumun birbirinden bağımsız olamayacağı ile ilgili olarak bkz. Holton (2005), Economy and Sociey, Routledge Press, London ve New York, s: 23-47.
} 
Turgut, E., Sarıöz Gökten, Y. \& Uçan, O. (2021). Eski ve yeni kurumsal ekole heterodoks bir bakış.

Fiscaoeconomia, 5(2), 404-417. doi: 10.25295/fsecon.891169

Yeni Kurumsalcıların heterodoks olarak değerlendirilip değerlendirilemeyeceğine yönelik tartışmalar yürütülecektir.

\section{Ana Akıma Bir Alternatif Olarak Heterodoks iktisat}

Heterodoks iktisat, en genel ifadeyle iktisadi analizlerde matematiğin ve tümdengelimin her koşulda ve her durumda tek geçerli yöntem olduğunu iddia eden ana akım teoriye bir meydan okumadır (Lawson, 2006: 492). Heteredoks iktisadın oldukça eski bir geçmişi olmasına rağmen "heterodoks" teriminin ekonomi sözlüklerinde kullanımı görece yenidir. Terim ilk kez 1947'de A. Gruchy'in Modern iktisadi Düşünce adlı eserinde Veblen geleneğinden gelen iktisatçılar için kullanılmıştır (Wrenn, 2007: 98). Dolayısıyla heterodoks iktisadın temellerinin Veblen ekseninde oluşturulduğu ve yerleşik iktisat öğretisine bir alternatif olduğunu söylemek yanlış olmayacaktır. Özellikle 1930-1980 arası dönemde kurumsalcı yazında sık sık heterodoks kavramsallaştırmasına yer verilir.

Heterodoks iktisadın entelektüel temelleri; birikimi, adaleti, sınıf ilişkilerini, cinsiyeti ve ırkı, kökeni kapsayacak şekilde toplumsal ilişkilere, iktisadi ve toplumsal yeniden üretim ilişkilerine, toplumsal faaliyetleri gerçekleştiren aktörlerin ihtiyaç duyduğu mal ve hizmetlerin akışını sağlayan fiili süreçlere dayanmaktadır. Bu ifade ediliş biçimiyle iktisat, toplumsal ve kültürel anlamda insan faaliyetleri ile ilişkilidir (Lee, 2008: 27).

Hetero kavramı çoğulculuk ve farklılık anlamına gelmekte ve bu okullara heterodoks okulları denmesinin temelinde de bu okulların temsilcileri arasında 1960'larda neoklasik-ortodoks yaklaşımlara karşı çıkan iktisatçıların yer alması yatmaktadır. Bu sebeple bu iktisat okullarına alternatif iktisat okulları adı da verilmektedir. Heterodoks kavramı ise monizm yani tekçilik karşıtı olarak kullanılmaktadır (Tomanbay, 2019: 42).

Genel hatlarıyla heterodoks iktisadın temel özellikleri şu şekilde sıralanabilir (Mearman, 2007: 3-4).

a) İktisadın anlaşılabilmesinde metodoloji önemli bir yere sahiptir.

b) İnsanların eylemleri toplumsal niteliktedir ve tamamen rasyonel değildir.

c) Bireysel faaliyetler daha çok kültür, gelenekler, alışkanlıklar ve rutinlerce yönlendirilmektedir.

d) İktisadi sistemler karmaşık ve öngörülemez olduğu için genel denge modeline şüpheyle yaklaşmak gerekmektedir.

e) Bireysel teoriler faydalı olsa bile toplu ve kolektif sonuç teorileri de yararlıdır, dolayısıyla hem birey hem de toplum birlikte düşünülmelidir.

f) Tarih ve zaman önemlidir.

g) Tüm iktisadi teoriler yanıltıcı olabilir ve çoğulculuk esastır.

h) Matematiksel ve istatistik tek geçerli yöntem ve diğerlerinden üstün olarak görülmemeli, iktisadi analizler diğer yöntemler ve veri türleri ile de mutlaka desteklenmelidir.

i) Gerçekler ve değerler birbirinden ayrı düşünülemez.

j) İktisadi sonuçların belirlenmesinde güç önemli bir yere sahiptir 
Turgut, E., Sarıöz Gökten, Y. \& Uçan, O. (2021). Eski ve yeni kurumsal ekole heterodoks bir bakış.

Fiscaoeconomia, 5(2), 404-417. doi: 10.25295/fsecon.891169

Çalışmanın ilerleyen kısımlarında öncelikle Eski-Yeni Kurumsal ekol ele alınacak ardından da heterodoks iktisadın yukarıda belirtilen özellikleri doğrultusunda bu iki ekolün heterodoks iktisattaki yeri üzerine tartışmalar yürütülecektir.

\section{Kurumsal İktisat Üzerine}

Kurumsal iktisat, kavramsal olarak 1918' de ilk kez Hamilton tarafından kullanılmıştır. Hamilton kavramı "iktisat Teorisine Kurumsal Yaklaşım” adlı çalışmada kullanmış ardından da kurumsal iktisat kavramı literatürde yerini almıştır. Hamilton bildirisinde, ortodoks teoriye meydan okuma ve alternatif kurumsal bir yaklaşım ortaya koyma gayretine girmiştir. Hamilton Kurumsal iktisadı, kurumlara ve kurumların iktisadi hayattaki etkilerine odaklanan bir düşünce akımı olarak ifade eder (Rutherford, 2004: 40).

Kurumsal iktisat denildiğinde tek bir teoriden bahsetmek mümkün olmamakta, kurum kavramı bazen bireylerin davranışlarını ifade ederken bazen de bireylerin uymaları gereken yasaları ve doğal hakları ifade edecek şekilde kullanılmaktadır. Bazen davranışlar kurumsaldır. Bazen statik değil dinamik analizler, duyguların yerine faaliyetler, bireysel eylemler yerine kitle eylemleri, genel denge analizi yerine yönetim, bırakınız yapsınlar bırakınız geçsinler anlayışındansa kontrol mekanizmalarını benimseyen teoriler kurumsal iktisat içerisinde değerlendirilmektedir (Commons, 1931: 648).

Daha önce de belirtildiği üzere kurumsal iktisadın neoklasik ekol kadar keskin çizgileri bulunmaz. Ancak genel olarak kurumsal iktisadın yöntemi muhalif olmaya ve farklı bir yolda yürümeye razı olmak, evrimci ve bütüncül bir ekonomi anlayışını benimsemek; metafizik, teolojik, ortodoks yaklaşımlarla iktisat yapmak yerine olguları öne çıkarmak, genel geçer yasaları reddetmek, toplumu ve toplumsal süreçleri dikkate almak, genel denge çözümlemelerinin ve neoklasik yaklaşımın sınırlılıklarının farkına varmak ve toplumsal yapının ortaya konulmasında teknolojinin önemini dikkati almak şeklinde ifade edilebilir (Samuels, 1995: 343-344).

Kurumsal ekol, iktisadi sistemlerin temelinde bireylerin değil kurumların olduğunu, bireyleri bu kurumlardan bağımsız bir biçimde ele almanın olanaksız olduğunu savunur. İnsan zihninin oluşturduğu bir yapı olarak kurumlar görülemez, hissedilemez ve ölçülemezler (North, 2002: 143).

Kurumsal iktisat açısından en önemli kavram kuşkusuz kurumdur. Ancak iktisat literatüründe kurum kavramına ilişkin net bir tanımlama ortaya koyulamamış ve tanımlar çeşitlilik göstermiştir. Kurumsal iktisat denildiğinde akla ilk gelen isim olan Veblen'e göre kurum, örgütsel varlıklar değil fikir kalıplarıdır. O kurumları erkek egemen düzende ortak olan gelenekler, davranış kurallarından oluşan yerleşik düşünce alışkanlıkları olarak görmez. Aksine Veblen bu toplumsal alışkanlıkların ve geleneklerin evrimini açıklamakla ilgilenmiştir. Kurumların mekaniğini tanımlamakla değil, fikirlerin türetilmesini analiz etmekle ilgilendiği için daha sonraki kurumsalcılardan ayrılmaktadır (Sowell, 1967: 189). Yine Veblen-Ayres-Foster paradigmasına göre kurum, toplumsal olarak belirlenmiş davranış kalıpları dizisi olarak tanımlanmaktadır. Davranış ise toplumun değer yapısı tarafından belirlenmektedir (Bush, 1983: 36). Yeni Kurumsal iktisatçılardan North ise kurumları, bir toplumdaki oyunun kuralları şeklinde ifade eder. Buna göre kurum insanlar arasındaki etkileşimi şekillendiren ve insanlar tarafından oluşturulmuş kurallar bütünüdür (1995: 54). Benzer şekilde Carden de kurumları, 
Turgut, E., Sarıöz Gökten, Y. \& Uçan, O. (2021). Eski ve yeni kurumsal ekole heterodoks bir bakış. Fiscaoeconomia, 5(2), 404-417. doi: 10.25295/fsecon.891169

oyunun kuralları olan ve insanların karşılık vereceği teşvikleri belirleyen resmi kurallar, resmi olmayan kurallar ve bunların uygulanma biçimleri şeklinde ifade etmiştir (2007: 36).

Kurumsal iktisat kendi içerisinde evrimsel bir süreç geçirmiştir. Kurumsal ekolü Eski ve Yeni Kurumcular şeklinde ikiye ayırmak mümkündür. En önemli temsilcileri arasında John Clark, Wesley Mitchell, John Common ve Thorstein Veblen'in bulunduğu Eski Kurumsal iktisat, hem neoklasik hem de Marksist teoriye eleştirel yaklaşır. Bu ekolün temel ilgi alanları arasında kaynak tahsisi, gelir dağılımı, fiyatların ve istihdamın nasıl belirlendiği gibi "iktisadi" analizler değil, bir bütün olarak kurumların evrimi ve ekonomide oynadıkları roldür. Eski Kurumsal iktisatçılar 1918-1947 dönemleri arasında özellikle Amerikan ekonomisinde etkili bir hareket oluşturmuştur. Eski Kurumsalcılar davranışları kısıtlayıcı ve kolaylaştırıcı olarak kurumların rolüne vurgu yapar. Buna göre değerleri, inançları ve tercihleri şekillendirmede kurumların önemli bir rolü vardır. Ayrıca Eski Kurumsalcılar fayda maksimizasyonu fikrini reddetmekte, toplumsal fenomenlerin ampirik ve eleştirel bir şekilde incelemesine vurgu yapmakta, hakim kurumların işleyişini eleştirel olarak incelemekte ve toplumsal değerlere önem vermektedir (Spithoven, 2019: 441).

Eski Kurumsal iktisadın temeli evrimsel ${ }^{6}$ Darwinci perspektife dayanır. Akımın kurucusu olan Veblen, felsefenin gücünü kullanarak yerleşik iktisadın düşünsel temellerini eleştiri süzgecinden geçirmiş ve onun görünmez el metaforu ya da doğal düzen gibi temel dayanaklarını yıkmaya çalışmıştır. Bu ekol, klasik iktisadın bireyi hedonist bir kalıba sokmasını ve hazcılığı güçlü bir şekilde eleştirmiştir. Çünkü bu düşüncenin iktisadı durağanlaştırdığı belirtmiştir. Veblen'e göre birey toplum zinciri içerisinden ayrılmamalıdır. Aksi takdirde birey etkinsizleşir ve iktisadi süreçten soyutlanır (Dura, 2020: 223).

Veblen, statik denge analizleriyle uğraşmak yerine evrim teorisine merak sarmıştır. İktisadın fizik kurallarıyla değil biyolojik kurallarla açıklanması gerektiğini savunur. Ona göre doğa birimleri evrimsel süreci analiz eder ancak neoklasik iktisat metodolojik anlamda evrimci olamaz. İktisadı matematiksel modellerle analiz etmek onu evrimci yapmaz (Veblen, 1898: 375). Veblen'in evrimci görüşü benimsemesinin iki önemli nedeni vardır. Bunlardan ilki, iktisadı statik bir hale getiren genel denge yaklaşımı ile açıklama çabalarıdır. İkinci olarak Veblen'in, toplumsal dünya ile gen ve doğal seçilim süreci arasında benzerlik kurmasıdır (Hodgson, 1994: 20).

Eski Kurumsal teori ile yerleşik iktisat olarak da bilinen neoklasik ekol arasında epistemolojik, ontolojik ve metodolojik anlamda önemli farklılıklar bulunmaktadır. Ontolojik olarak neoklasik iktisat, yalnızca tipik ekonomik gücü modellemek uğruna önemli faktörlerin göz ardı edildiği izole bir ekonomik dünya hakkındadır. Eski Kurumsal iktisat ise gerçek hayattaki ekonomi ve toplum hakkındadır. Epistemolojik olarak neoklasik iktisat tümdengelim ile karakterize edilir. Eski Kurumsal iktisat ise yöntem olarak tümevarımı benimser. Ampirik verilere dayanarak trendler gözlemlenir. Metodolojik olarak ise neoklasik ekonomi mikro temellere sahiptir. Genel olarak ekonomideki aktörler veya toplumsal grupları, bireylerin kümeleri olarak yorumlar. Eski Kurumsal iktisat ise net bir biçimde makro yönelime sahiptir. Toplumlar, evrenin

\footnotetext{
${ }^{6}$ Evrim düşüncesinin iktisada yansımalarıyla ilgili olarak bkz. Gökten, K. (2006), İktisatta evrim düşüncesi ve evrimci iktisatın teknolojiye yaklaşımı. Akdeniz Üniversitesi iktisadi ve Idari Bilimler Fakültesi Dergisi, 6(11), 2444.
} 
Turgut, E., Sarıöz Gökten, Y. \& Uçan, O. (2021). Eski ve yeni kurumsal ekole heterodoks bir bakış.

Fiscaoeconomia, 5(2), 404-417. doi: 10.25295/fsecon.891169

ve ortaya çıkan küresel toplumun evrimsel sürecinin bir parçasıdır. Hiçbir toplum bu süreçten kaçamaz ve kendisine ait olan kurumsal yapı da dâhil olmak üzere kendi gelişim aşamasını kabul etmek zorundadır. İktisadi ve toplumsal performans, mevcut kurumsal çerçeveler tarafından belirlenmektedir (Keizer, 2007: 4-5).

Yeni Kurumsal iktisat kavramsallaştırmasını ise ilk olarak Oliver Williamson ortaya atmış ve böylece Eski-Yeni Kurumsalcılar şeklinde ayrıma gidilmiştir (Coase, 1998: 72). 1970'li yıllarda gelişmeye başlayan Yeni Kurumsal iktisat kökenlerini Coase'nin (1937) firma analizine, Hayek'in $(1937,1945)$ bilgi üzerine yazılarına, Chandler'in (1962) endüstriyel gelişim tarihine ayrica Simon (1947), Arrow (1963), Davis ve North (1971), Williamson (1971, 1975, 1985), Alchian ve Demsetz (1972), Macneil (1978), Holmström'a (1979) dayanmaktadır. Bununla birlikte en tanınmış temsilcileri Coase, Williamson ve North'tur. Yeni Kurumsal iktisat günlük yaşamı yöneten toplumsal, iktisadi ve politik kurumlarla ilgilenmektedir. Ayrıca Yeni Kurumsal iktisat, eski okulun metodolojik bütüncüllüğünü benimsememektedir. Yeni Kurumsal iktisat, açıklamalarını daima bireylerin hedefleri, planları ve eylemleri açısından metodolojik bireyciliği takip etmektedir (Klein, 1998: 457).

Kendinden önceki kurumsalcıların neoklasik teoriyi tersine çevirmek veya değiştirmek için yaptığı birçok girişimin aksine Yeni Kurumsal iktisat, neoklasik teoriyle uyumlu bir teori inşa etme çabasına girmiştir (North, 1993: 1). Kurumsal iktisadın kendi içerisinde farklılaşmasının temeli, neoklasik iktisada bakış tarzlarıyla açıklanmaktadır. Çünkü Eski Kurumsal iktisatçılar, klasik ve neoklasiklerin soyut varsayımlarını açıkça ve tamamen reddederken Yeni Kurumsal iktisatçılar, neoklasik iktisadın varsayımını tamamen reddetmekten kaçınarak onun varsayımlarını değiştirmek ve geliştirmek üzerine odaklanmışlardır (Richter, 2005: 171).

Bu noktada Yeni Kurumsal iktisadın neoklasik iktisat ile benzerliği analizlerine kıtlıkla başlaması ve rekabet varsayımında yatmaktadır. Yeni Kurumsalcılar, ekonomiyi kısıtlamalara tabi bir seçim teorisi olarak görmekte ve kurumların analizinin önemli bir parçası olarak fiyat teorisini kullanmaktadır. Ayrıca onlara göre, göreli fiyatlardaki değişiklikler kurumlarda değişimi tetikleyen temel bir güçtür. Yeni Kurumsalcıların neoklasik teoriyi değiştirerek genişlettiği noktalar arasında; rasyonalite varsayımını değiştirmenin yanı sıra, kurumları kritik bir kısıt olarak ele almaları ve kurumlar ile üretim maliyetleri arasındaki bağlantı olarak işlem maliyetlerinin rolünü analiz etmeleridir. Yine iktisadi analize; iktisat teorisini, fikirleri ve ideolojileri dâhil ederek, politik süreci ekonomilerin performansında kritik bir faktör olarak, ekonomilerin farklı performansının kaynağı olarak ve "verimsiz" piyasaların açıklaması olarak modelleyip genişleterek neoklasik teoriye katkıda bulunmuştur (North, 1993: 2).

Daha önce de ifade edildiği üzere metodolojik olarak Yeni Kurumsal iktisat, neoklasik iktisada benzerlik göstermektedir. Dolayısıyla, ontolojik olarak gerçeklik, iktisadi dünyayı oluşturan aksiyomlara göre çerçevelenmekte ve epistemolojik olarak tümdengelim yöntemi kullanılmaktadır. Ayrıca Yeni Kurumsalcılar da tıpkı neoklasikler gibi metodolojik olarak mikro yönelimlidir (Keizer, 2007: 6).

Özetle Yeni Kurumsal iktisat farklı teorisyenlerin ortaya attığı fikirlerin bir araya gelmesiyle ortaya çıkmış bir ekoldür. Buna bağlı olarak da Yeni Kurumsal iktisatçılar her ne kadar ortak noktalar üzerinde buluşsalar da bazı konularda birbirlerinden farklı bakış açılarına sahip 
Turgut, E., Sarıöz Gökten, Y. \& Uçan, O. (2021). Eski ve yeni kurumsal ekole heterodoks bir bakış. Fiscaoeconomia, 5(2), 404-417. doi: 10.25295/fsecon.891169

olmuşlardır. Dolayısıyla Yeni Kurumsal iktisat birçok düşünce okulunu bünyesinde barındırır. Yeni Kurumsal ekole ait düşünce okulları ve teorisyenler Şekil 1'de verilmiştir.

Şekil 1: Yeni Kurumsal İktisadın Dalları

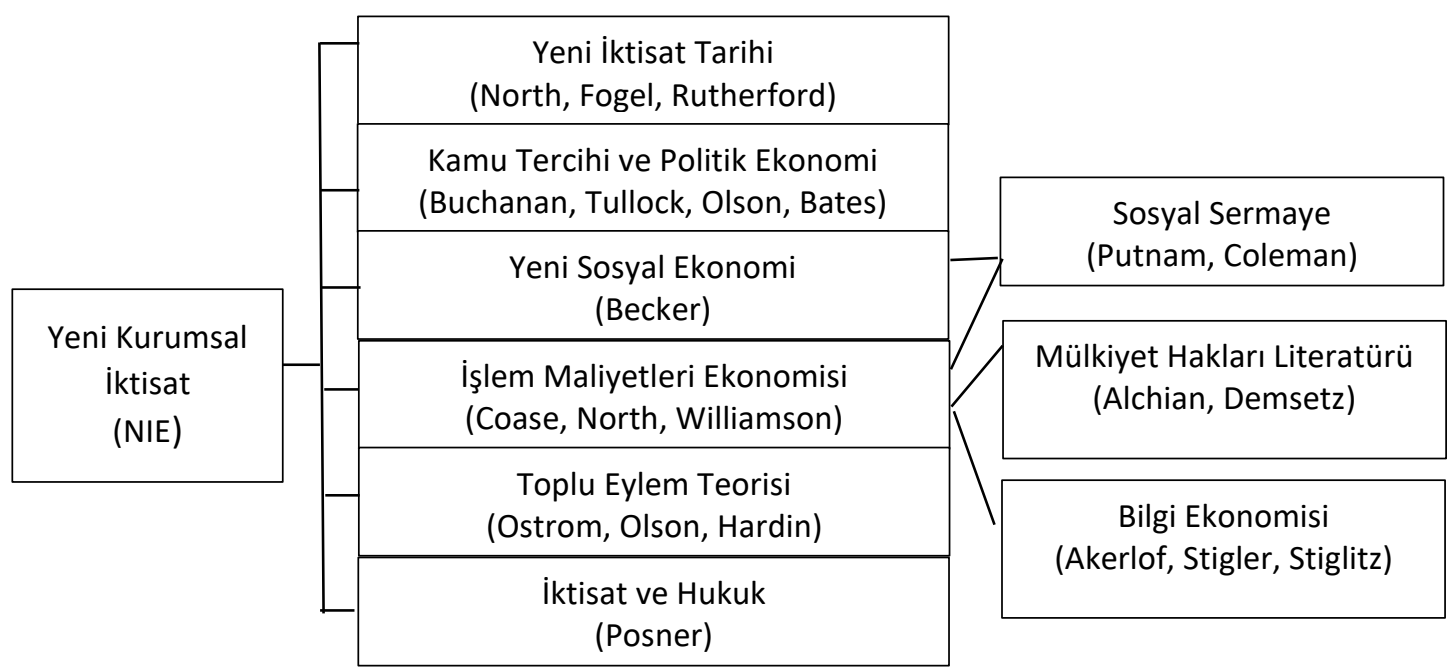

Kaynak: Kherallah ve Kirsten, 2002: 114.

Yeni Kurumsal iktisadın dallarını oluşturan bu ekoller ve bunların teorisyenleri bazı konularda neoklasik iktisada ters düşerken bazı konularda onunla benzer düşünürler. Yeni Kurumsalcılar, neoklasik iktisadı özellikle metodolojik ve politik açıdan reddetmişlerdir. Çünkü neoklasik iktisat teorisi, matematiksel formülasyonu ve açıklamayı kolaylaştırmak için rutin olarak görünen ve genellikle hem fiziksel hem de psikolojik açıdan oldukça gerçekçi olmayan varsayımlar benimsemektedir. Neoklasik teorilerde firmaların karşılaştığı talep eğrilerinin sonsuz esnek olması ve girdiler ile çıktıların sonsuz bölünebilir olması varsayımları Yeni Kurumsalcılar tarafından eleştirilmiş ve gerçek dışı bulunmuştur. Varsayımların fazlasıyla sınırlayıcı olması, iktisat teorisi ile teorinin tanımlamayı ve açıklamayı iddia ettiği ekonomik sistem arasında bir boşluk yaratmaktadır (Posner, 1993: 74-75).

Yeni Kurumsal iktisat, mikro iktisadın genel varsayımlarına gerçeklik katmaktadır. Bireyler eylemlerini, kararlı ve tutarlı bir tercih sıralamasıyla maksimize etmek amacıyla çaba sarf etmektedirler. Ancak kurumsal iktisatçılar bireylerin bilişsel sınırlar, yetersiz bilgi, anlaşmaların izlenmesi ve uygulanmasındaki zorluklardan dolayı bu şekilde davrandıklarını ileri sürmektedir. Analizin temel birimi olarak işlemi kabul eden Yeni Kurumsalcılara göre, değişimi talep eden taraflar bilginin pahalı olduğu bir dünyada işlem maliyetlerinden tasarruf etme çabası içerisine girerken, bazıları fırsatçı davranmakta ve rasyonellik sınırlandırılmaktadır (Powell ve Dimaggio, 1991: 3-4).

Williamson, Yeni Kurumsal îktisat ifadesini kullanarak onu Commons ve Veblen'in öncülük ettiği Eski Kurumsal iktisattan ayırmıştır. Eski Kurumsal Okul, kurumların ekonomik davranışı açıklamada ve etkilemede anahtar faktör olduğunu, ancak çok az analitik titizliğe sahip olduğunu ve neoklasik iktisat çerçevesinin dışında bulunduğunu savunmuştur. Öte yandan neoklasik ekol, kurumların rolünü görmezden gelmiş ve ekonomik birimlerin neredeyse bir 
Turgut, E., Sarıöz Gökten, Y. \& Uçan, O. (2021). Eski ve yeni kurumsal ekole heterodoks bir bakış. Fiscaoeconomia, 5(2), 404-417. doi: 10.25295/fsecon.891169

boşlukta faaliyet gösterdiğini varsaymıştır. Yeni Kurumsal iktisatçılar kurumların önemli bir rolü olduğunu kabul etmişler, ancak neoklasik ekole Eski Kurumsalcılar kadar katı yaklaşmamışlardır. Ayrıca kurumların neoklasik iktisat çerçevesinde analiz edilebileceğini savunmuşlardır. Bir diğer ifadeyle Yeni Kurumsal iktisat altında, neoklasik ekonominin mükemmel bilgi, sıfır işlem maliyeti ve tam rasyonellik gibi ekonominin bazı gerçekçi olmayan varsayımları gevşetilmiş ancak kendi çıkarı peşinde koşan birey varsayımına sadık kalınmıştır (Kherallah ve Kirsten, 2002: 111).

\section{Sonuç ve Değerlendirme}

iktisat literatüründe yöntem tartışmaları her daim vardır. İktisadi ekollerin ortodoks mu yoksa heterodoks mu oldukları daha çok neoklasik senteze yakınlığı veya uzaklığına bakılarak karar verilir. Kurumsal iktisadın Eski ve Yeni Kurumsal iktisat şeklinde iki gruba ayrılması ve ortaya çıkan metodolojik farklılıklar iktisat yazınının ilgisini çekmiş ve söz konusu ekollerin ortodoks $\mathrm{mu}$, heterodoks mu olduklarına yönelik tartışmalar alevlenmiştir.

Kurumsal iktisat neoklasik iktisadi düşünce akımına karşı bir akım olarak doğup gelişmiş, adeta ana akım olacak kadar da benimsenir. Kurumsalcılar iktisat biliminin temeline bireyler yerine kurumları yerleştirirken sosyoloji ve psikoloji gibi diğer sosyal bilimlerden de yararlanmaktadır. Hemen hemen tüm kurumsalcılar kurum kavramı üzerine odaklanmış olsa da genel geçer bir kurum kavramının tanımına ve kapsamına yönelik bir uzlaşıya varılamamıştır.

Kurumsalcılar genel olarak neoklasik öğretinin ileri sürdüğü denge olgusuna ve bırakınız yapsınlar varsayımına karşı durmuşlar ve onun yerine iktisadi sistemlerin açık ve dinamik bir yapıya sahip olmasının gerekliliği ile ekonomide denetimin zorunluluğuna vurgu yapmışlardır. Bu savunu, kurumsal iktisadın yerleşik iktisada yönelttiği ve böylelikle bu iktisada karşı geldiği en önemli eleştirilerden biri olmuştur. Bu durum kurumsal iktisadın heterodoks iktisat olarak kabul edilmesinin önemli bir gerekçesidir.

Ayrıca neoklasik ekolde ekonomik yapının çözümlenmesine yönelik kurulan modellerde ceteris paribus varsayımıyla birçok faktör sabit varsayılmıştır. Bu durum kurumsalcılar tarafından; tüketicilerin zevk ve tercihleri, toplumsal yapının özellikleri, dini inanışlar gibi ekonomi üzerinde fazlasıyla önemli olan unsurların devre dışı bırakılmasına neden olduğu ve böylelikle doğru sonuçlara ulaşılmasını engellediği, ekonominin durağan hale gelmesine neden olduğu nedeniyle eleştirilmiştir. Buna ek olarak neoklasik ekolün en önemli aksiyomlarından biri olan bireylerin rasyonel olduğu varsayımına da eleştirel yaklaşmışlardır. Çünkü insanların gerçek hayatta tamamen kendi çıkarlarını düşünerek hareket etmediğini ve dolayısıyla sınırlı rasyonalitenin geçerli olduğunu savunmuşlardır. Eski Kurumsal iktisatçıların, neoklasik teorinin en temel varsayımlarını eleştirmeleri ve iktisadı sosyal bir bilim olarak kabul etmeleri, iktisatta evrimsel bir sürecin var olduğu savunusu Eski Kurumsal iktisadın heterodoks kapsamında değerlendirilmesi gerektiğini doğrulamaktadır. Yine Kurumsalcıların heterodoks bir iktisat okulu olduğunun en önemli kanıtlardan bir diğeri de neoklasik teorinin üzerine kurulmuş olduğu hazcılığın reddedilip bireylerin davranış ve tercihlerinin oluşmasında geleneklerin, alışkanlıkların belirleyici olduğu vurgusudur. Bu açıklamalar ışığında kurumsal iktisadın ve özellikle Eski Kurumsal iktisadın heterodoks iktisat olarak değerlendirilmesi doğru olacaktır.

Yukarıda sayılan durumlara karşın Yeni Kurumsal iktisadın, ana akım öğretiye karşı bazı varsayımları reddederken bazılarını kabul etmesi Yeni Kurumsal iktisadın heterodoks bir iktisat 
Turgut, E., Sarı̈̈z Gökten, Y. \& Uçan, O. (2021). Eski ve yeni kurumsal ekole heterodoks bir bakış.

Fiscaoeconomia, 5(2), 404-417. doi: 10.25295/fsecon.891169

okulu olup olmadığına dair şüpheler barındırmaktadır. Örneğin Yeni Kurumsal iktisat, neoklasik öğretinin kıtlık ve rekabet gibi kavramlarını benimsemiş, mikro analizler yapmış ancak rasyonellik ve tam bilgi gibi gerçek dışı varsayımlarını reddetmiştir. Son olarak Yeni Kurumsalcılar, devletin iktisadi hayattaki sınırlı rolü ve fonksiyonları olduğunu savunmuşlardır. Dolayısıyla Yeni Kurumsalcılar, neoklasik teoriyi tamamen eleştirip terk etmek yerine, bazı noktalarda onunla uzlaşmış ve neoklasik ekolün katı çekirdeği içerisinden ayrılmamışlardır. Yeni Kurumcu iktisadın adeta kurumcu iktisat ile neoklasik teori arasında bir köprü kurduğu ve iki ekolü uzlaştırmaya yönelik adımlar attığı söylenebilir. Bu açıdan Yeni Kurumsal iktisadın heterodoks bir iktisat okulu olduğu savına şüpheli yaklaşılması gerekmektedir.

\section{Kaynakça}

Beed, C. (1991), "Philosophy of Science and Contemporary Economics: An Overview", Journal of Post Keynesian Economics, 13(4), 459-489.

Buğra, A. (2003), iktisatçılar ve insanlar. İstanbul: Iletişim Yayınları.

Bush, P. D. (1983), "An Exploration of the Structural Characteristics of a Veblen-Ayres-Foster Defined Institutional Domain", Journal of Economic Issues, 17(1), 35-66.

Carden, A. (2007), "Christian Ethics, Formal Institutions, and Economic Growth", American Review of Political Economy, 5(1), 34-53.

Coase, R. (1998), "The New Institutional Economics", The American Economic Review, 88(2), 72-74.

Commons, J. R. (1931), "Institutional Economics", American Economic Review, 21, 648-657.

Dura, Y. C. (2020), Asıl ve Yeni Kurumsal Iktisat: Farklılıklar ve Benzerlikler Üzerine Bir Çözümleme. Aktan, C. C. (Editör). Kurumsal iktisat, Kurallar ve Kurumların iktisadi Gelişme Açısından Önemi. İzmir. SOBIAD Hukuk ve Iktisat Araştırmaları Merkezi Yayınları, 216-261.

Gökten, K. (2006), “iktisatta Evrim Düşüncesi ve Evrimci İktisatın Teknolojiye Yaklaşımı”, Akdeniz Üniversitesi Iktisadi ve Idari Bilimler Fakültesi Dergisi, 6(11), 24-44.

Hodgson, G. M. (1994), Precursors of Modern Evolutionary Economics: Marx, Marshall, Veblen and Schumpeter. R. W. England (ed), Evolutionary Concepts in Contemporary Economics içinde, The University of Michigan Press, 9-35.

Holton, R. (2005), Economy and Society. London and New York: Routledge Press.

Keizer, P. (2007), The Concept of Institution in Economics and Sociology, A Methodological Exposition. Utrecht School of Economics Tjalling C. Koopmans Research Institute, Discussion Paper Series, 07-25.

Kherallah, M. \& Kirsten, J. F. (2002), "The New Institutional Economics: Applications for Agricultural Policy Research in Developing Countries", Agrekon, 41(2), 110-133. doi: 10.1080/03031853.2002.9523589

Klein, P. G. (1998), “New Institutional Economics”, Available at SSRN 115811, 456-489. 
Turgut, E., Sarı̈̈z Gökten, Y. \& Uçan, O. (2021). Eski ve yeni kurumsal ekole heterodoks bir bakış.

Fiscaoeconomia, 5(2), 404-417. doi: 10.25295/fsecon.891169

Lawson, T. (2006), "The Nature of Heterodox Economics", Cambridge Journal of Economics, 30, 483-505. doi:10.1093/cje/bei093

Lee, F.S. (2008), “Heterodox Economics", The Long Term View, 7(1), 23-30.

Mearman, A. (2007), "Teaching Heterodox Economics Concepts", Handbook for Economics Lecturers, 5, 1-40.

North, D. C. (1993), "The New Institutional Economics and Development", Economic History, 9309002, 1-8.

North, D. C. (1995), "The New Institutional Economics and Third World Development", The New Institutional Economics and Third World Development, 41-57.

North, D. (2002), Kurumlar, Kurumsal Değişme ve Ekonomik Performans. Çeviren Gül Çağalı Güven, 1. Baskı, Sabancı Üniversitesi Yayınları, İstanbul.

Polanyi, K. (1996), The Great Transformation, The Great Transformation: The Political and Economic Origins of Our Time, Beacon Press, Boston.

Posner, R. A. (1993), "The New Institutional Economics Meets Law and Economics", Journal of Institutional and Theoretical Economics (JITE), 149(1), 73-87.

Powell, W. W. \& Dimaggio, P. J. (1991), The Institutionalism in Organizational Analysis. Chicago: University of Chicago Press.

Richter, R. (2005), "The New Institutional Economics: Its Start, Its Meaning, Its Prospects", European Business Organization Law Review, 6, 161-200.

Rutherford, M. (2004), "Institutional Economies at Columbia University", History of Political Economy, 36(1), 31-78.

Samuels, W. (1995), "The Making of a Relativist and Social Constructivist: Remarks upon Receiving the Veblen-Commons Award", Journal of Economics Issues, 29(1), 343-358.

Sowell, T. (1967), "The Evolutionary Economics of Thorstein Veblen”, Oxford Economic Paper, 19(2), 177-198.

Spithoven, A. (2019), "Similarities and Dissimilarities between Original Institutional Economics and New Institutional Economics", Journal of Economic Issues, 53(2), 440-447. doi: 10.1080/00213624.2019.1594532

Tomanbay, M. (2019), “iktisadi Düşüncenin Gelişimi ve İktisat Okulları”, Ufuk Üniversitesi Sosyal Bilimler Enstitüsü Dergisi, 8(15), 31-45.

Veblen, T. B. (1898), "Why is Economics not an Evolutionary Science?", The Quarterly Journal of Economics, 12(4), 373-397.

Wrenn, M. (2007), "What is Heterodox Economics? Conversations with Historians of Economic Thought", Forum for Social Economics, 36(2), 97-108. doi: 10.1007/ s12143-007-90025 
Turgut, E., Sarıöz Gökten, Y. \& Uçan, O. (2021). Eski ve yeni kurumsal ekole heterodoks bir bakış.

Fiscaoeconomia, 5(2), 404-417. doi: 10.25295/fsecon.891169

Etik Beyanı: Bu çalışmanın tüm hazırlanma süreçlerinde etik kurallara uyulmuştur. Aksi bir durumun tespiti halinde Fiscaoeconomia Dergisinin hiçbir sorumluluğu olmayıp, tüm sorumluluk çalışmanın yazarlarına aittir.

Yazar Katkıları: Ecem TURGUT, çalışmanın tüm bölümlerinde özellikle de çalışmanın şekillenmesi aşamasında katkı sağlamıştır. Yeliz SARIÖZ GÖKTEN, çalışmanın tüm bölümlerinde özellikle de revizyon aşamasında çalışmaya katkı sağlamıştır. Okyay UÇAN ise çalışmanın tüm bölümlerinde özellikle de çalışmanın kontrol aşamasında çalışmaya katkı sağlamıştır. Çalışmada 1. yazarın katkı oranı: \%35, 2. yazarın katkı oranı: \%35 ve 3. yazarın katkı oranı $\% 30$ 'dur.

Çıkar Beyanı: Yazarlar arasında çıkar çatışması yoktur.

Teşekkür: Yayın sürecinde katkısı olan hakemlere ve editör kuruluna teşekkür ederiz.

Ethics Statement: Ethical rules were followed in all preparation processes of this study. In case of detection of a contrary situation, Fiscaoeconomia has no responsibility and all responsibility belongs to the authors of the study.

Author Contributions: Ecem TURGUT has contributed to all parts of the study, especially in the shaping of the study. Yeliz SARIÖZ GÖKTEN contributed to all parts of the study, especially during the revision process. Okyay UÇAN has contributed to all parts of the study, especially in the control process of the study. Contribution rate of the first author in the study: $35 \%$, contribution rate of the second author: $35 \%$ and contribution rate of the third author is $30 \%$.

Conflict of Interest: There is no conflict of interest between the authors.

Acknowledgement: We thank the referees and editorial board who contributed to the publishing process. 
Turgut, E., Sarıöz Gökten, Y. \& Uçan, O. (2021). Eski ve yeni kurumsal ekole heterodoks bir bakış.

Fiscaoeconomia, 5(2), 404-417. doi: 10.25295/fsecon.891169

\section{A Heterodox View to the Old and New Institutional School}

\section{Ecem TURGUT, Yeliz SARIÖZ GÖKTEN, Okyay UÇAN}

\section{Extended Abstract}

The basis of efforts to explain the economy with generally valid laws is based on positivism. Since the eighteenth century, positivism is accepted as the only way to access information, and criteria are determined in order to distinguish between science and non-science. While the information that meets these criteria is considered being scientific, on the contrary, information that does not meet the criteria is regarded unscientific. Based on positivism, an effort has been made to formulate laws that cover all societies and conditions, sovereign of time and space in economics as well as in natural sciences. Thus, the orthodox and heterodox distinction appeared while the discussions began that method in economics.

When it comes to orthodox theory, the first thing that comes to mind is neoclassical economics. Orthodox theory, as in other natural sciences, has attempted to create an economy that has universal and generally valid laws. In this direction, physics is taken as an example, economics is tried to be placed within the framework of general equilibrium, thus ignoring the relationship between economy and society, but instead abstractions, mathematics and modeling are included in economics. Accordingly, economic events have been explained with concepts such as general equilibrium, rational individual, utility, invisible hand, and free market. In order to remove the obstacles in front of the positive economics; value judgments, customs, religion, morality, habits, class relations and all similar social relations are excluded from the analysis. In this direction, the heterodox economic movement emerged and made strong criticisms of the Orthodox approach. Heterodox approaches stated that an economic theory that is valid in every environment, society and time as orthodoxes claim cannot exist. Heterodox economists, by including tastes and preferences, religious beliefs, culture and traditions, and class relations in their analysis, brought up the importance of society in terms of economics. In the history of economics, many schools have fallen into the distinction between orthodox and heterodox stream, and this issue has become a subject of controversy in the literature. One of the most important of these schools has been institutional economics.

Institutional economics emphasized the importance of institutions while opposing the method of the neoclassical school based on rational human, profit and utility maximization, deduction and abstraction. In addition, institutional economics is divided into two different branches as Old and New Institutional economics. The New Institutionalists have criticized the traditional institutionalists' total opposition to neoclassical economics. While rejecting the unrealistic assumptions of the neoclassical school, also tried to preserve the solid core of neo-classics. As a result of this distinction among institutionalists, discussions about whether institutional economics are orthodox or heterodox have been constantly on the agenda in the economic literature. In this respect, while some economists evaluate institutional economics within the heterodox economy stream, some economists approached the issue suspiciously. In this direction, first, the basic features of heterodox approach and institutional economics have been revealed in this study. Afterwards, the distinction between the Old and the New 
Turgut, E., Sarıöz Gökten, Y. \& Uçan, O. (2021). Eski ve yeni kurumsal ekole heterodoks bir bakış. Fiscaoeconomia, 5(2), 404-417. doi: 10.25295/fsecon.891169

Institutionalist school is exposed and discussions are made about whether the Old-New Institutionalists could be considered as heterodox.

While institutionalists generally opposed the balance and laissez-faire assumption suggested by neoclassical, they emphasized the necessity of an open and dynamic structure of economic systems and the necessity of control in the economy. This has been one of the most important criticisms of institutional economics to mainstream economics. Therefore, as a result of the evaluation made within the study, these features are seen as an important reason for the acceptance of institutional economics as heterodox economics.

In addition, while many factors are accepted as constant with the assumption of ceteris paribus, in the models established for the analysis of the economic structure in the neoclassical school, that these factors can be effective in terms of the relationship between variables has been ignored. It has been criticized by institutionalists for eliminating the factors that are extremely important in the economy such as the tastes and preferences of consumers, the characteristics of the social structure, and religious beliefs and thus preventing the achievement of correct results and causing the economy to become stagnant. In addition, they are critical of the idea that individuals are rational, one of the important assumptions of neo-classics. Because they argued people do not act entirely on their own interests in actual life and therefore limited rationality is valid. Old Institutional economists criticize the most basic assumptions of neoclassical theory and accept economics as a social science, and the assumptions that economics cannot be considered independent of society confirm that Old Institutional economics should be evaluated within the scope of heterodox. In addition, Institutionalists refuse hedonism based on neoclassical theory and emphasize that traditions and habits are determinants in the formation of individuals' behaviors and preferences, which confirms that the Old Institutional Economics should be evaluated in a heterodox trend. In the light of these explanations, it would be correct to consider institutional economics and especially Old Institutional economics as heterodox economics.

Unlike the old institutionalists, the New Institutional Economics rejecting some assumptions and accepting others against mainstream doctrine. For this reason doubts arise whether the New Institutional Economics is a heterodox school of economics. For example, the New Institutional Economics adopted neoclassical concepts such as scarcity and competition, conducted micro-analysis but rejected its unrealistic assumptions such as rationality and perfect knowledge. Finally, the New Institutionalists argued that the state should have a limited role in economic life. Therefore, instead of completely criticizing and abandoning neoclassical theory, the New Institutionalists came to terms with it at some points and did not leave the solid core of the neoclassical school. At this point, it would not be wrong to say that the New Institutional Economics established a bridge between institutional economics and neoclassical theory and took steps to reconcile the two schools. In this respect, it would be the best decision to be suspicious of the argument that the New Institutional Economics is a heterodox school of economics. 